\title{
A EDUCAC̣̃̃O SUPERIOR NO BRASIL DIANTE DA MUNDIALIZAÇÃO DO CAPITAL
}

\author{
Deise Mancebo" \\ Universidade do Estado do Rio de Janeiro, Rio de Janeiro - RJ, Brasil \\ João dos Reis Silva Júnior* \\ Universidade Federal de São Carlos, São Carlos - SP, Brasil \\ Daniel Schugurensky*** \\ Arizona State University, Tempe - Arizona, EUA
}

RESUMO: O artigo discute o processo de expansão da educação superior brasileira, considerando as demandas do capitalismo monopolista contemporâneo de predominância financeira. O texto é um estudo de caráter exploratório e sua construção apoia-se em pesquisa bibliográfica e análise documental de problemáticas convergentes e necessárias para a compreensão do tema, adotando uma perspectiva de análise que conjuga aspectos quantitativos e qualitativos. $\mathrm{Na}$ sequência, o artigo discute o processo de mundialização do capital sob a predominância financeira, as expressões da mundialização no Estado brasileiro e a forma como se deu a expansão da educação superior nas últimas décadas no Brasil, considerando os setores público e privado. Especial atenção é dada para a produção de conhecimento mercantilizada, pelo impacto que tem provocado na cultura institucional universitária.

Palavras-chave: Mundialização do capital. Educação superior. Produção do conhecimento.

http://dx.doi.org/10.1590/0102-4698162033

"Doutora em Educação pela Pontifícia Universidade Católica de São Paulo, com pós-doutorado pela Universidade de São Paulo. Professora Titular do Programa de Políticas Públicas e Formação Humana da Universidade do Estado Rio de Janeiro (PPFH/UERJ). Coordenadora do Observatório da Educação (OBEDUC) "Políticas da Expansão da Educação Superior no Brasil" e da Rede Universitas/Br. E-mail: $<$ deise.mancebo@gmail.com>.

“"Doutor em Educação: História, Política, Sociedade pela Pontifícia Universidade Católica de São Paulo (PUC/SP). Pós-doutorado em Sociologia Política pela Universidade de Campinas (UNICAMP); em Economia pela Universidade de São Paulo (USP) e em Economia pela Universidade de Londres. Professor associado da Universidade Federal de São Carlos (UFSCar). Livre-docente pela Universidade de São Paulo (USP). Coordenador adjunto do Observatório da Educação (OBEDUC) "Políticas da Expansão da Educação Superior no Brasil". E-mail: < joaodosreissilvajr@gmail.com>.

"*DDoutor em Educational Policy Studies pela University of Alberta (Canada). Professor da Arizona State University (USA), no School of Public Affairs Department e no School of Social Transformation Department. Diretor do School of Public Affairs. 


\section{BRAZILIAN HIGHER EDUCATION IN FACE OF CAPITAL GLOBALIZATION}

ABSTRACT: The paper discusses the process of expansion of Brazilian higher education, considering the demands of contemporary monopoly capitalism of financial dominance. The text is an exploratory study based on literature and document analysis of converging problems that are necessary to understand the subject by adopting a perspective of analysis that combines quantitative and qualitative aspects. In sequence, the paper discusses the capital globalization process under the financial dominance. The paper discusses how that process affects the Brazilian state and how it has oriented the expansion of higher education in recent decades in Brazil, considering the public and private sectors. Production of commodified knowledge has received a special attention as it has a significant impact in the university institutional culture.

Keywords: Capital globalization. Higher education. Production of knowledge.

\section{INTRODUÇÃO}

O exame das razões que levaram à recente expansão da educação superior no Brasil constitui-se em notório desafio. Debater essa questão educacional, tomando como referência as demandas do capitalismo monopolista contemporâneo de predominância financeira é tarefa mais complexa ainda, impossível de se alcançar, em sua plenitude, num texto. Todavia, é o desafio central que pretendemos perseguir aqui, pelo menos em suas linhas mais gerais, trabalhando com a hipótese central de que o regime de acumulação com a predominância financeira provoca mudanças reais no processo de trabalho, na indústria, nos aparelhos de Estado e, no que aqui nos interessa, na educação.

Assim, na sequência do artigo, buscaremos discutir o processo de mundialização do capital sob a predominância financeira, as expressões da mundialização no Estado e na educação brasileira e a forma como se deu a expansão da educação superior nas últimas décadas no Brasil, considerando os setores público e privado. Especial atenção será dada para a produção de conhecimento mercantilizada, pelo impacto que tem provocado na cultura institucional universitária e pelos fortes vínculos que apresenta com a mundialização do capital. $\mathrm{O}$ texto é um estudo de caráter exploratório e, para sua construção, apoiamo-nos em pesquisa bibliográfica e análise documental de problemáticas convergentes e necessárias para a compreensão do tema, adotando uma perspectiva de análise que conjuga aspectos quantitativos e qualitativos.

Deve-se registrar que boa parte das fontes e das análises apresentadas pertence a um coletivo de mais de 200 pesquisadores da Rede Universitas/Br, que participam do projeto integrado "Políticas 
da Expansão da Educação Superior no Brasil’. São colegas incansáveis na tentativa de aprofundar as diversas facetas da educação superior no país. A eles pertence boa parte dos dados e comentários expostos, mesmo que as conclusões, eventualmente apressadas, sejam nossas.

Na sequência, o artigo discute o processo de mundialização do capital sob a predominância financeira, as expressões da mundialização no Estado brasileiro e a forma como se deu a expansão da educação superior nas últimas décadas no Brasil, considerando os setores público e privado e abrangendo a formação (massificada) e a produção de conhecimento (mercantilizada), para a qual se deu mais atenção pelo impacto que tem provocado na cultura institucional universitária.

\section{O PROCESSO DE MUNDIALIZAC̣ÃO DO CAPITAL SOB A PREDOMINÂNCIA FINANCEIRA}

As transformações no capitalismo contemporâneo resultaram em um novo padrão de acumulação mundial que permitiu a livre circulação dos capitais em escala planetária. Chesnais (1996) denomina esse processo, que se consumou nas últimas décadas, de mundialização (do capital), que sob a égide dos Estados Unidos, resulta num modo de funcionamento específico do capitalismo, predominantemente financeiro e rentista. Para ele, esse processo desenvolve-se sob três dimensões principais: "intercâmbio comercial, investimento produtivo no exterior [IED] e os fluxos de capital monetário, ou capital financeiro" (CHESNAIS, 1996, p. 51).

$\mathrm{Na}$ tentativa de ir à raiz da questão Netto e Braz (2007) analisam que, na realidade, a financeirização resultou do processo de

[...] superacumulação e, ainda, da queda das taxas de lucro dos investimentos industriais registrada entre os anos setenta e meados dos oitenta. [Nesse contexto], um montante fabuloso de capital disponibilizou-se então sob a forma de capitaldinheiro (ou capital monetário). Parte desse capital foi investido na produção e, especialmente, no setor de serviços em outros países pelas corporações imperialistas (representando o chamado investimento externo direto/IED) [mas] parte substantiva permaneceu no circuito da circulação buscando valorizar-se nesta esfera. (NETTO; BRAZ, 2007, p. 231)

E os autores continuam afirmando que "à medida que o capitalismo se desenvolveu, um segmento de capitalistas passou a viver exclusivamente desse capital que conservaram sob a forma monetária" (NETTO; BRAZ, 2007, p. 232). Trata-se da camada de capitalistas rentistas, que não se responsabilizam por investimentos produtivos. Portanto, o processo de mundialização do capital sob a predominância financeira acaba por resultar num regime de acumulação centrado 
no poder das instituições financeiras, cujos principais agentes são os bancos, os fundos de pensão, os fundos de investimentos, as seguradoras e outras empresas financeiras especializadas.

A mundialização do capital - que na acepção de Chesnais (1996) difere da globalização ou internacionalização do capital, fenômenos observáveis desde meados do século XIX - é a marca do processo vivido pelo capitalismo desde as últimas décadas do século XX e ela caracteriza-se

[...] pela descentralização de grandes empresas, do ramo industrial, por exemplo, cujas unidades se multiplicam e se espalham por diversas regiões e países, com menores custos e maiores vantagens quanto à força de trabalho (mais barata), matéria prima, legislação trabalhista, universidades que pesquisam e formam mão de obra especializada para empresas com subsídio estatal, etc. A força econômica dessas empresas sobrepor-se-ia à de muitos Estados nacionais e suas instituições republicanas, como a universidade e instituições de pesquisa. (SGUISSARDI, 2015, p. 95)

Para atender a esse processo, na tentativa de garantir a retomada da expansão do capital, especialmente de sua rentabilidade na esfera financeira, a partir dos anos 1980, sob a hegemonia da doutrina neoliberal, os Estados nacionais promovem "reformas", gerando uma repartição da riqueza cada vez mais concentrada, em favor das instituições financeiras ${ }^{1}$. Essas reformas, invariavelmente, traduzem uma deserção dos Estados de sua função de provedor de direitos e serviços sociais (saúde, educação, dentre outros) e aprofundam seus vínculos com o mercado mundial.

Conforme Chesnais (2005), a pressão exercida pelos investidores para a extração crescente de lucros das empresas exige mais produtividade, novas formas de organização do trabalho, novas formas de organização e gestão, uso intensivo de novas tecnologias, com fortes danos econômicos e sociais para os assalariados. Estes encontram-se envolvidos com desemprego estrutural, rebaixamento de salários, intensificação da jornada, precarização das condições do trabalho e a necessidade de uma forte acomodação psicofísica e da sua sociabilidade. Como observa Sguissardi (2015):

Nesse contexto de mundialização do capital financeirizado, que cobra aumento de produtividade, supervaloriza a competição e a rentabilidade empresariais de bens e serviços, a ciência e a educação superior adquirem um valor cada dia maior como efetivas mercadorias. Da mesma forma, valorizam-se as instituições, universidades e institutos de pesquisa, com potencial de produzi-las. Cada vez mais se verifica, na economia atual, maior predominância dos bens imateriais sobre os materiais e a universidade passa a ser vista como essa nova empresa produtora, ainda que indireta, de mais valor. (SGUISSARDI, 2015, p. 98) 
Assim, pode-se afirmar que grandes transformações ocorreram nas universidades e na educação superior em boa parte do mundo, engendradas, em última instância, pela hegemonia do capital financeiro, sob a égide do capital portador de juros e do capital fictício. As frações financeiras foram insistentes e vitoriosas nas diversas tentativas de reposicionar sua hegemonia mundial. Impingiram, por exemplo, novos contornos à área dos serviços. Seu núcleo hegemônico pôde impor um novo marco ao comércio mundial com a criação da Organização Mundial do Comércio (OMC), em 1995, com a definição da educação no rol de serviços a ser liberalizado no escopo do General Agreement on Trade in Services (GATS) e, mais recentemente, no Trade in Services Agreement (TISA) 2. Em síntese, "as corporações e os países do núcleo hegemônico lograram espraiar suas ações em escala mundial, a partir de regulamentações com alcance planetário" (LEHER, 2015b, p. 31).

\section{EXPRESSÕES DA MUNDIALIZAC̣ÃO NO ESTADO BRASILEIROE A EDUCAC̣ÃO SUPERIOR}

Todo esse processo também provocou impactos no Brasil, mesmo que seus efeitos tenham aparecido um pouco mais tarde. $\mathrm{O}$ trânsito da década de 1980 para a de 1990 foi o marco histórico de profundas mudanças estruturais na sociedade brasileira e também na cultura institucional da educação superior, que se prolonga até os dias atuais. Essas mudanças cobrem os governos dos três últimos presidentes brasileiros e as apresentaremos, em linhas gerais, seguindo periodização proposta por Silva Júnior e Schugurensky (2014) para a compreensão da dinâmica do capitalismo e da educação superior no país.

A primeira fase detectada pelos autores tem como base econômica a demanda imposta ao país em face de sua aderência à globalização, gerada pelo predomínio do capital financeiro e tem seu ápice em 1995. Ela se expressa concretamente na edição do Plano Diretor da Reforma do Aparelho do Estado (BRASIL, 1995), reforma que afeta todas as instituições e, consequentemente, as instituições de educação superior (IES). A elaboração do Plano foi liderada pelo Ministério da Administração Federal e da Reforma do Estado (MARE), onde "os policymakers brasileiros produziram a institucionalidade para o exigido alinhamento do país ao movimento realizado no nível mundial" (SILVA JÚNIOR; SCHUGURENSKY, 2014, p. 34), qual seja, ao momento histórico que o capitalismo experimentava de transição do regime de acumulação monopolista para o de predominância financeira. 
De um modo bem geral, pode-se afirmar que o Plano Diretor pretendia inserir a educação entre os "serviços competitivos ou não exclusivos do Estado" e estabelecia um novo precedente para as parcerias público-privadas na educação superior brasileira.

Segue-se uma segunda fase que abrangeu os mandatos do presidente Fernando Henrique Cardoso (FHC), mas também o início do primeiro mandato do governo de Lula da Silva (2003-2007). Ela é marcada pela edição de inúmeras legislações, decorrentes do Plano, que afetaram as mais diversas instâncias, órgãos estatais e instituições republicanas em geral e, em particular, as IES. Os traços que passam a ser perseguidos, de um modo bem geral, na educação superior brasileira são: a pesquisa aplicada; cursos mais rápidos, inclusive apoiados em novas tecnologias de informação e comunicação; processos avaliativos ou de regulação calcados em resultados, entre outros. Adicionalmente, cabe destacar a gradativa perda da autonomia universitária, diretamente relacionada à emergência de uma heteronomia de gestão e de uma nova relação entre a universidade e o setor empresarial, que começa a ter curso. Todas essas mudanças já podiam ser observadas nos países de economia central, seja os da União Europeia, especialmente com o Processo de Bolonha (1999), mas também se apresentavam de modo bastante acabado no Canadá e, principalmente, nos Estados Unidos da América.

A terceira etapa tem início em meados do primeiro mandato da gestão do presidente Lula da Silva e prossegue em parte do governo de Dilma Rousseff (de 2011 a 2013, pelo menos). Nessa etapa, a contrarreforma continua por meio de um grande número de leis, decretos e portarias, regulando o trabalho docente, os currículos, as avaliações etc. Sua principal característica, no entanto, seria a emergência de programas com forte potencial de mudança institucional e a expansão da educação superior, como o Programa de Apoio ao Plano de Reestruturação e Expansão das Universidades Federais (REUNI) (BRASIL, 2007) que inaugura, em larga escala, formas de financiamento por meio de contratos de gestão -; o incremento à educação a distância (EAD), em especial com a criação do sistema Universidade Aberta do Brasil (UAB) (BRASIL, 2006); a proliferação de cursos tecnológicos nos moldes dos community colleges. Especificamente quanto à rede privada, o redimensionamento do Fundo de Financiamento Estudantil (FIES) ${ }^{3}$ e a generalização das isenções fiscais, previdenciárias e de renúncia fiscal pelo Programa Universidade para Todos (PROUNI) (BRASIL, 2005a) foram as principais iniciativas, cobertas com fundo público, que se pode responsabilizar pela expansão. 
Uma síntese dessas três etapas revela que, indiscutivelmente, a educação superior brasileira viveu um amplo processo de expansão após 1995. Se tomarmos os dados referentes às matrículas, por exemplo, temos a seguinte situação: entre 1995 e 2014, ocorreu um crescimento no número total de matrículas (presenciais e à distância), que passou de 1.759.703, em 1995, para 7.828.013, em 2014, com um crescimento aproximado da ordem de 345\%, num espaço de tempo de 20 anos $^{4}$.

Se, por um lado, essa expansão deve ser percebida como positiva por ampliar o acesso da população ao ensino superior, é necessário atentar para alguns efeitos perversos desse mesmo processo, pois, indiscutivelmente, o que mais se expandiu no período foram as matrículas nas instituições privadas, que tiveram um crescimento da ordem de 454\%, enquanto na rede pública o aumento foi de $180 \%$ somente ${ }^{5}$.

Sempre é bom lembrar que o critério para o oferecimento de cursos e de matrículas nas instituições privadas são suas planilhas financeiras. Assim, a expansão se dá sob a influência direta de demandas mercadológicas, a partir dos interesses da burguesia desse setor de ampliar a valorização do seu capital, com a venda de serviços educacionais.

Isso faz com que haja uma enorme quantidade de cursos de forte apelo mercantil oferecidos nas regiões mais ricas do país e que dão pouquíssimas contribuições para o desenvolvimento econômico, social e cultural do país ou da própria região, ao mesmo tempo em que locais e áreas profissionais que mais necessitam de reforços são abandonados. O critério financeiro atinge, também, a qualidade dos cursos oferecidos, restringindo as possibilidades profissionais dos estudantes e a contribuição que essas IES poderiam dar para o desenvolvimento das diferentes áreas de conhecimento (MANCEBO; VALE; MARTINS, 2015, p. 35).

Consideramos importante acrescentar uma quarta etapa às definidas por Silva Júnior e Schugurensky (2014), correspondente ao fim do primeiro mandato da presidenta Dilma Rousseff à presente data. O que se verifica nesse período diz respeito à "adaptação" do país à conjuntura de crise internacional. No nosso entendimento, trata-se de uma crise capitalista mundial, uma crise orgânica e geral do capitalismo, cujo marco foi o ano de 2008. Os impactos dessa crise manifestamse de forma diferenciada em termos geográficos e temporais, mas é inegável que, no último período, impactou com força a América Latina e o Brasil, em movimentos estruturais que abalaram as bases sociais da própria reprodução política, impossíveis de serem analisadas em profundidade nesse texto. Em linhas gerais deve-se registrar: 
1 - A evolução da política nacional ocorre num pano de fundo de uma nova situação geopolítica na América Latina. Na virada do milênio, havíamos assistido a um certo giro à esquerda. De acordo com Domingues (2015), esse giro foi "modesto em seus resultados", mas teve o mérito de remar contra a maré global, e "ele significou a implantação de um social liberalismo de cunho progressista, tendo em seu centro políticas de equidade que suavizaram de forma humanitária e economicamente estimulante as agruras das massas de miseráveis da região mais desigual do mundo”. Implicou, ainda, uma maior centralidade de Estados "na coordenação da vida econômica e um distanciamento dos ditames mais severos do capital financeiro", sem que a igualdade propriamente tenha sido alcançada.

\footnotetext{
Esse giro atingiu seus limites e, finda a bonança das commodities e a fartura de recursos que proporcionou durante a década de 2000, somente enfrentamentos sociais distributivos mais aguçados poderiam permitir que [a economia] retomasse seu ímpeto, levando a políticas sociais mais universalistas e custosas, bem como a uma mudança mais decidida de modelo econômico. (DOMINGUES, 2015)
}

2 - Tais enfrentamentos não ocorreram e a vitória do rentismo, institucionalizado na crise de 2008, só aprofundou as contradições estruturais da ordem burguesa no plano mundial, principalmente, no que tange ao orçamento público, impondo a adoção das políticas de ajuste (austeridade) neoliberal.

3 - Inicialmente, os ajustes foram aplicados nos países centrais do capitalismo, mas, a partir de meados da década de 2010, assistimos à intensificação da ofensiva neoliberal na América Latina, sob a retomada da influência hegemônica dos Estados Unidos na região.

Nessa conjuntura complexa, na qual se articulam crise econômica e crise política, as instituições de ensino superior (especialmente as públicas) veem-se afetadas, primeiramente, pela recessão e cortes sistemáticos advindos da federação e de diversos entes federativos.

Nas instituições de educação superior públicas, o movimento de expansão de matrículas e cursos - como foi o caso do REUNI -, verificado pelo menos até 2013, é refreado em função dos ajustes, deixando às instituições a amarga tarefa de reconfigurar diversos procedimentos internos, para fazer frente à expansão (do período anterior) que lhes legou mais alunos, cursos, campi e forte interiorização, sem o devido financiamento.

A estratégia mais imediatamente observada é a dos cortes de verbas de manutenção e renovação, abandonando a infraestrutura física dos campi. Todavia, as dificuldades não se esgotam aí. Outro movimento 
perceptível nas IES públicas de acomodação à atual conjuntura refere-se ao grande peso que tem sido dado ao ensino, em detrimento das demais atividades próprias à universidade. Por seu turno, o ensino - muitas vezes aligeirado, voltado às exigências de mercado ou ainda mediante o uso da educação a distância (EAD) - nem sempre se encontra adaptado às necessidades dos novos estudantes que adentraram na universidade pública, criando sérios problemas de evasão.

$\mathrm{Na}$ rede pública, as possibilidades de expansão parecem recair nos Institutos Federais de Educação, Ciência e Tecnologia (IFs), com forte direcionamento às demandas do mercado. Temos por hipótese que essa rede, no campo público, poderá manter um certo ritmo de expansão, pois é composta por instituições que racionalizam o uso de recursos financeiros, o que é almejado por qualquer Estado capitalista, em tempos de crise.

Para finalizar a análise de acomodação das IES públicas (federais e estaduais) à atual conjuntura e aos cortes, é preciso mencionar as diversas estratégias de desregulamentação e ataque aos direitos trabalhistas que vêm ocorrendo. Diversos governos, além do federal, têm adotado, de forma mais recorrente, "alternativas" para reduzir o custo da força de trabalho, por meio da implementação de variadas estratégias de precarização, com vistas à transformação das relações de trabalho e redução da folha de pagamento. Uma situação que vem se generalizando e que está a requerer investigações mais aprofundadas refere-se à terceirização da força de trabalho auxiliar - mas que poderá ser estendida para os trabalhadores das atividades fins -, com contratos com empresas que negam aos funcionários, inclusive, direitos trabalhistas básicos e proteção.

Quanto às IES privado-mercantis, os efeitos da crise não são os mesmos. Na realidade, são opostos. Conforme detalhado diagnóstico elaborado por Sguissardi (2015, p. 103) "as IES do país com fins lucrativos e, em especial, as mantidas por empresas de capital aberto e envolvidas no mercado acionário, [...] hoje, apresenta-se como o setor de maior rentabilidade dentre os setores atuantes na BM\&FBovespa". O mesmo autor, acompanhando a evolução do índice do Ibovespa e do valor das ações, em 2013 e 2014, conclui “[...] em dois anos a Kroton teve uma valorização de suas ações na Bolsa de 314,87\%; a Estácio, 240,97\%; e a Anhanguera, nos dois anos que correram até 28 de março de 2014, 85,89\%" (SGUISSARDI, 2015, p. 122).

Esse diferencial no enfrentamento da crise pode ser atribuído a vários fatores. Primeiramente, à forte indução estatal. Conforme Reis (2016, p. 25): 
Em 2014, o governo federal liberou R \$13,154 bilhões para o Fies e o Prouni. Essas despesas passaram a representar $12,32 \%$ do orçamento total sob supervisão do MEC. Em termos financeiros, os recursos destinados à expansão da educação superior privada, por meio do Fies e do Prouni, cresceram 880,42\%: de R $\$ 1,342$ bilhão, em 2003, para R\$13,154 bilhões, em 2014.

Adicionalmente, essas empresas também introduziram inovações gerenciais (enxugamento de quadros, precarização do trabalho $)^{6}$ e têm adotado um ensino de qualidade discutível, inclusive com o uso intensivo da modalidade a distância.

Para concluir esse diagnóstico preliminar da expansão, podemos emitir a síntese apresentada por Silva Júnior e Spears (2012), que nos parece bastante atual. Para esses autores, o movimento de "acomodação" da educação superior brasileira ao capitalismo monopolista contemporâneo (de predominância financeira) "desdobra-se em duas largas dimensões concomitantes: [...] o processo de mercantilização da produção do conhecimento e a certificação em massa dos estudantes de graduação e de pós-graduação" (SILVA JÚNIOR; SPEARS, 2012, p. 9), que desenvolveremos a seguir.

\section{A FORMAC̣̃̃O MASSIFICADA}

Como já discutimos, a predominância financeira põe exigências ao Estado, bem como demanda novos ordenamentos jurídicos para as políticas públicas, incluindo as destinadas à formação na educação superior. Em linhas gerais, esse novo ciclo de movimentação do capital exige do futuro trabalhador mais produtividade, flexibilidade para adaptação às novas formas de organização do trabalho e às novas formas de gestão, competências gerais para lidar com a introdução de avanços tecnológicos, bem como uma ampla disposição para suportar a intensificação e precarização do trabalho humano, hoje presente na maior parte das ocupações, exigindo dos trabalhadores um redobrado equilíbrio físico e subjetivo.

Obviamente, essas diversas e complexas aptidões sofrem imensas variações conforme o campo de trabalho considerado e, consequentemente, demandam formações também variadas. No entanto, de um modo geral, pode-se identificar dois grandes processos de formação que qualificam tipos diferentes de mão de obra, exigidos por diferentes patamares da economia em tempos de predominância financeira: (1) a formação necessária a empregos que exigem mais qualificação, que normalmente são mais estáveis e que pagam melhor, e (2) a formação da maioria, designada por 
certificação em massa, destinada a empregos mal pagos, precários, com uma maior exploração da força de trabalho e que exigem um menor (ou nenhum) nível de conhecimento técnico. A formação de primeiro tipo ocorre principalmente na pós-graduação stricto sensu e em cursos mais valorizados socialmente das universidades de melhor qualidade. A de segundo tipo é fornecida por cursos de pósgraduação lato sensu e pelo restante da graduação.

Ainda sobre essa questão, deve-se destacar a dinâmica do setor privado, que detém a maior taxa de matrículas na graduação aproximadamente $75 \%$ das matrículas da educação superior presenciais e a distância -, conforme publicação do último Censo da Educação Superior (BRASIL, 2015). São empresas e, enquanto tal, precisam ter retorno lucrativo, seu parâmetro não é o interesse público geral, a importância do ponto de vista cultural, científico e político, e nem o suprimento de força de trabalho para o mercado ${ }^{7}$. As análises de Leher e Motta (2014) sintetizam muito bem a especificidade do setor privado:

Inexiste uma relação direta entre a qualidade da força de trabalho requerida pelo capital e a expansão do serviço educacional no setor privado. Este setor não objetiva necessariamente suprir a força de trabalho para os diversos ramos da produção, pois sua racionalidade é outra: a venda de serviços com fins de lucro para os fundos de investimentos e bancos. [...] Entretanto, tal descompasso não é necessariamente irracional para os interesses gerais do capital. Por sua própria natureza mercantil [...], os processos de socialização empreendidos pelas corporações educacionais são congruentes com a pedagogia demandada pelo capital, difundindo valores do capital humano e do capital social e, ademais, a formação do Exército Industrial de Reserva (EIR) é altamente funcional para o capital. (LEHER; MOT'TA, 2014, p. 61, grifo nosso)

\section{A PRODUÇÃO DE CONHECIMENTO MERCANTILIZADA}

O desenvolvimento, combinado e desigual, do capitalismo em escala mundial e de predominância financeira também introduziu a mercantilização na produção e na disseminação do conhecimento. Sem dúvida, este foi o campo da educação superior mais afetado pelas mudanças econômicas, tendo curso na Europa, América Latina e no país que teve precedência nesse processo: os Estados Unidos da América.

Burawoy (2015, p. 43) observa que a

[...] invasão do mercado na produção e na disseminação do conhecimento combinou-se com sistemas nacionais de educação superior preexistentes para produzir resultados muito diversos, gerando uma série de crises que impactam diferentes níveis de cada sistema de forma distinta. 
Todavia, há semelhanças entre os diversos sistemas, sobre as quais nos deteremos.

Nos EUA, a colaboração entre a universidade e as indústrias já ocorre há algum tempo. No entanto é, sobretudo, a partir da década de 1980 que essa associação toma um impulso significativo, aumentam os níveis de patentes e licenças de conhecimentos produzidos na universidade e sua comercialização ocorre mais rapidamente. ${ }^{8}$

$\mathrm{Na}$ Europa, conforme Lima (2015), a análise de documentos de política científica e de governação da educação superior, provenientes de instituições internacionais e supranacionais, designadamente da União Europeia, revela, com frequência, concepções utilitaristas e instrumentais quanto à produção do conhecimento científico. A análise indica, ainda, forte indução à "cultura empresarial orientada para o mercado e o lucro, e ainda pelo exemplo das universidades empreendedoras e inovadoras dos Estados Unidos da América” (LIMA, 2015, p. 12).

No Brasil, deve-se destacar, preliminarmente, que esse movimento de mercantilização da produção do conhecimento não é encontrado em todas as universidades e nem em todas as instituições públicas e isso porque somente algumas delas têm pesquisa e pósgraduação institucionalizadas plenamente. São essas IES, ou grupos dentro delas, que têm sido instadas à produção de um novo conhecimento: "o conhecimento matéria prima", passível de ser transformado em produtos, processos e serviços" (SILVA JÚNIOR, 2016, p. 125) ou o tipo de conhecimento que esteja relacionado à possibilidade de lucros imediatos no âmbito econômico. Leher (2015b), estabelecendo paralelo com o conhecimento estratégico desenvolvido nos países do núcleo hegemônico do capitalismo, chega a afirmar que as instituições de pesquisa brasileiras ajustam-se "à mera condição de prestadoras de serviços de adaptação de tecnologias inscritas em bens de capital, bem como de serviços e processos que corporações não desejam realizar no [seu] país" (LEHER, 2015b, p. 31).

De todo modo, trata-se de um conhecimento preponderantemente aplicado, guiado pela economia, que é protegido por patentes, direitos autorais e marcas registradas e que é orientado para um tratamento em que Ciência, Tecnologia e Inovação (CT\&I) formem um trinômio indissociado ${ }^{10}$. Esse anseio de articulação da universidade ao sistema produtivo remonta a períodos anteriores, à ditadura militar no Brasil (1964-1984), mas os passos mais incisivos para tal só são dados a partir do governo de FHC.

Conforme histórico traçado por Oliveira, Ferreira e Moraes (2015), a Lei de Diretrizes e Bases - LDB - (Lei n 9.394, de 20 de dezembro de 1996), vincula a educação escolar mais fortemente 
ao sistema produtivo, indicando o desenvolvimento de competências para o mundo do trabalho (BRASIL, 1996). Adicionalmente, a articulação universidade/sistema produtivo, pautada agora pela busca constante da inovação, foi ainda mais intensificada no Plano Nacional de Educação - PNE - (2001-2010, aprovado pela Lei no 10.172, de 9 de Janeiro de 2001). As discussões que fizeram parte da $2^{a}$ Conferência Nacional de Ciência, Tecnologia e Inovação ( $\left.2^{a} \mathrm{CNCTI}\right)$, ocorrida em 2001, também foram razoavelmente orientadas nessa direção, tanto que o termo "inovação" passou a fazer parte do nome do próprio evento. Os autores assim analisam a questão:

[...] a inovação deixaria de ser um aspecto pontual e aleatório na produção de C\&T, para se tornar o carro-chefe, a raison d'être, dos investimentos do país nesse setor e também das políticas públicas para as demais áreas. O que se propunha era uma estratégia centrada no papel do conhecimento gerado por diferentes atores, alicerçada na aproximação cada vez maior entre os empresários e a universidade brasileira, para a constituição de um sistema nacional de CT\&I. (OLIVEIRA; FERREIRA; MORAES, 2015, p.138)

Assim, desde a segunda metade dos anos 1990, intensificaramse no país a discussão e as ações políticas voltadas para inovação,

[...] sobretudo, por meio de criação de marcos legais [mas], também, mediante incentivos fiscais, subvenção, crédito subsidiado e criação de incubadoras de empresas, polos e parques tecnológicos, apoio à pesquisa e desenvolvimento, compras governamentais em áreas consideradas prioritárias. (OLIVEIRA; FERREIRA; MORAES, 2015, p. 127)

Os governos de Lula da Silva e de Dilma Rousseff deram continuidade a essa tendência, buscando viabilizar a aproximação entre a educação superior e as empresas. Em 2 de dezembro de 2004, foi aprovada a Lei n 10.973, também conhecida como "Lei da Inovação", que dispunha sobre incentivos à inovação e à pesquisa científico-tecnológica, promovia a criação e a consolidação de laços entre universidades, institutos tecnológicos e empresas, estimulando a participação de institutos de ciência e tecnologia no processo de inovação empresarial. Além disso, a Lei de Inovação criou todo um arcabouço jurídico capaz de viabilizar a incubação de empresas no espaço público ao estimular a utilização da infraestrutura pública para fins de desenvolvimento tecnológico privado. Ela facultava aos docentes o recebimento de incentivos financeiros ao desenvolverem projetos em parceria com empresas, assim como autorizava o afastamento dos docentes de suas atividades acadêmicas para se dedicarem às inovações nas empresas. 
A tendência a aprofundar o vínculo do conhecimento produzido nas universidades com o sistema produtivo também é explícita na $3^{\mathrm{a}}$ e na $4^{\mathrm{a}}$ Conferência de Ciência, Tecnologia e Inovação, ocorridas em 2005 e 2010, respectivamente, assim como no IV Plano Nacional de Pós-graduação (PNPG) 2005-2010 (BRASIL, 2005b) e no V Plano Nacional de Pós-graduação (PNPG) 20112020 (BRASIL, 2010). Sinteticamente, os dois últimos documentos propõem uma flexibilização do modelo de pós-graduação, de modo a atender aos setores acadêmico e não acadêmico, sugerindo a formação de técnicos e pesquisadores especializados para atuar nas empresas públicas e privadas. Em especial, o último PNPG é mais incisivo na convocação da universidade e de sua estrutura acadêmico-científica, técnica e pedagógica a contribuir na inserção do Brasil num sistema econômico mundial e competitivo por mercados, estimula, ainda, a diminuição temporal entre a produção de conhecimento e a sua apropriação (pública ou privada) (BRASIL, 2010, p. 309). Pretende fazer do conhecimento e da tecnologia uma poderosa ferramenta do desenvolvimento econômico e social e "neste quadro a parceria entre a Universidade, o Estado e as empresas dará lugar ao chamado modelo da tríplice hélice" (BRASIL, 2010, p. 18).

Um último documento merece citação: a Lei $\mathrm{n}^{\circ} 13.243$, de 11 de janeiro de 2016, chamada de Marco Legal da Ciência, Tecnologia e Inovação, que altera a Lei de Inovação Tecnológica. O novo Marco permite, entre outros aspectos, que professores em regime de dedicação exclusiva desenvolvam pesquisas dentro de empresas e que laboratórios universitários sejam usados pela indústria para o desenvolvimento de novas tecnologias (em ambos os casos, com remuneração). Autoriza que a União financie, faça encomendas diretas e até participe de forma minoritária do capital social de empresas com o objetivo de fomentar inovações e resolver demandas tecnológicas específicas do país. Digno de destaque é que as empresas envolvidas nesses projetos podem manter a propriedade intelectual sobre os resultados (produtos) das pesquisas. O novo código é bastante recente e requer acompanhamento rigoroso para que se possam analisar os impactos que trará para a produção do conhecimento e para a universidade como um todo. O Sindicato Nacional dos Docentes das Instituições de Ensino Superior (ANDES-SN) foi incisivo na crítica à nova legislação porque ela:

[...] aprofunda a privatização da ciência e tecnologia públicas, legalizando parcerias público-privadas na área e possibilitando transferência de recursos, estrutura, propriedade intelectual e pessoal de instituições públicas para usufruto da iniciativa 
privada, [...] alarga as vias de privatização do fundo público na área, prejudicando o caráter público de universidades e institutos, [possibilita] a criação de Instituições Científicas, Tecnológicas e de Inovação (ICTs) com estatuto de Organizações Sociais (OS), [que poderão] captar recursos públicos e privados e intermediar a prestação de serviços entre as instituições públicas e o mercado, [...] estimula que os docentes se tornem empreendedores, criando ICTs dentro das instituições para captar recursos. [Trata-se de] um avanço vigoroso do processo de privatização dos recursos humanos e patrimônio científico públicos. (ANDES-SN, 2016, p. 1)

Deve-se registrar que para inovar é preciso rigoroso planejamento, pois o retorno dos recursos investidos, o registro de patentes e a venda de novos produtos ou serviços, que orientam parte significativa dos esforços desenvolvidos nas universidades brasileiras, devem gerar resultados de curto prazo.

Conforme análise de Bianchi e Braga (2009), com o aumento da concorrência em escala global, com a compressão do ciclo de produção real de valor e o consequente estabelecimento de novos critérios de governança corporativa:

[...] os diferentes sistemas nacionais de pesquisa - sejam eles estatais, semipúblicos ou privados - passaram a ser pressionados por resultados de curto prazo. Os investimentos tangíveis ou intangíveis em pesquisa distanciaram-se daquela experiência histórica sustentada por um tipo de compromisso com horizontes de longo prazo que foi assegurado até meados dos anos 1980, tanto nos países de capitalismo avançado quanto em alguns países de capitalismo semiperiférico. (BIANCHI; BRAGA, 2009, p. 2)

Nesse processo, nos constrangimentos da produtividade acadêmica rápida (e aligeirada), muitos docentes se veem forçados a fazer a opção de aderir às demandas particularistas impostas em editais de financiamento à pesquisa, oferecendo serviços às empresas e a setores públicos, muitos transformados em organizações sociais (entidade pública de gestão privada). É, até certo ponto, uma forma de minimizar os impactos dos cortes nos orçamentos das instituições, que "tem forçado estas a uma adaptação subordinada ao mercado, às exigências da divisão do trabalho e à adoção de modos de organização e de gestão típicos do mundo econômico" (LIMA, 2015, p. 14).

Os novos valores que passaram a guiar as instituições poderiam ser sintetizados pela privatização do conhecimento, em busca de lucros pelas universidades e a reivindicação das corporações em ser prioridade antes do cidadão. A relevância econômica sobrepõe-se, claramente, à relevância cognitiva, social e cultural do conhecimento. Para tal, é exigido um professor empreendedor, disposto a produzir uma ciência útil e comercializável, que minimiza os efeitos dos cortes e ajustes perpetrados pelo Estado e, correlativamente, aumenta a 
dependência da universidade em relação ao mercado e às grandes corporações empresariais e financeiras. Fato é que a universidade pública brasileira que produz conhecimento alterou radicalmente sua cultura institucional ao passar por tantas mudanças de perfil e se ver frente a tantos novos compromissos, para os quais não foi criada e que a enraíza mais e mais num capitalismo de predominância financeira.

A leitura dos documentos sobre o tema (e de seus analistas críticos) deixa a amarga sensação de que se trata de políticas impostas, seja pela indução provocada pelos diversos órgãos de financiamento ou, ainda, pelas rigorosas avaliações, dentre as quais se destaca a da Coordenação de Aperfeiçoamento de Pessoal de Nível Superior (CAPES), em relação à pós-graduação. Para sobreviver, é obrigatório inovar, principalmente por meio de uma forte vinculação com o sistema produtivo, ou melhor, com as empresas!

Todavia, essa é somente uma parte do conto, pois se deve reconhecer que a subordinação não é uma imposição externa à universidade, que mecanicamente é seguida pelos que nela trabalham, mas resulta da adesão de uma parcela (cada vez mais considerável) de docentes a essa refuncionalização da universidade em prol das demandas da economia.

\section{CONSIDERAÇÕES FINAIS}

A documentação analisada neste texto, bem como a leitura crítica de autores que têm pesquisado a educação superior no Brasil, tendem a demonstrar, com razoável grau de evidência, que, ao longo das últimas décadas, especialmente após 1995, promoveu-se uma incessante busca pela expansão do sistema de educação superior no país, mas traduzida, no que tange à formação, em massificação, um processo de "universalização" que reduz ao máximo a formação às necessidades estritas do mercado de trabalho (BRUNO, 2011). Obviamente, a massificação apresenta fortes variações conforme a organização acadêmica (pública ou privada), a modalidade de ensino (presencial ou a distância), o tipo de curso (mais ou menos nobre), o nível de ensino (graduação ou pós-graduação) e até variações geográficas (que infelizmente não puderam ser exploradas no artigo).

Defendemos, ainda, a hipótese de que, a partir de 2014 (fim do primeiro mandato da presidenta Dilma Rousseff), a situação de expansão inverteu-se, pelo menos para o polo público do sistema de educação superior, em função da adaptação do país à conjuntura de crise 
estrutural, levando as IES a amargarem com a forte recessão e cortes sistemáticos advindos da federação e de diversos entes federativos.

Ao tratar da produção do conhecimento, demos destaque à mercantilização, à maior vinculação entre as universidades e as empresas, buscando compreender os nexos mais amplos do controle e exploração da produção do próprio conhecimento como mercadoria que, juntamente com o movimento de financeirização e desregulamentação, colabora para que o capitalismo se (re)organize.

Em síntese, por um lado, a expansão da economia em âmbito global está associada à incorporação de avanços tecnológicos que demandam conhecimentos cada vez mais especializados, rapidamente aplicáveis e que resultem em mais lucros para a fração da burguesia envolvida. Por outro lado, requer a exigência de nova qualificação da força de trabalho e diminuição de seu custo, remetendo, com frequência, a processos de mera massificação.

Tanto na formação quanto na produção do conhecimento, o quadro é bastante desanimador e a questão que nos colocamos, para terminar, vai na direção da formulada por Oliveira, Ferreira e Moraes (2015, p. 156): "como sobreviver no meio acadêmico sob essa pressão e, ainda por cima, pensar criticamente?" Como romper o silêncio cúmplice, quanto aos planos, programas e atividades oficiais, que sugerem que a universidade se converta em agência meramente executora e acrítica em relação às políticas públicas de competência do Estado?

A resposta não é simples, obviamente. Preliminarmente, consideramos que para tornar a universidade relevante, tanto em termos sociais quanto em termos científicos, urge uma reconciliação dos seus intelectuais com o conhecimento crítico, reflexivo e recuperador da missão histórica da universidade no processo civilizatório, por isso mesmo, um conhecimento insubmisso aos interesses mercantis. Em seguimento, seja qual for o movimento de sublevação, ele deve ser coletivo. Por fim, há que se considerar que a problemática universitária atual nos países capitalistas dependentes, como é o nosso caso, apresenta proporções mais devastadoras do que nos países do centro do capitalismo. A reversão desse quadro de heteronomia "não será possível nos espaços estritamente universitários e, tampouco, apenas pelos protagonistas diretos da universidade, os professores, técnicos e administrativos e os estudantes" (LEHER, 2015a, p. 11). Assim, gostaríamos de acompanhar a hipótese desenvolvida por Leher (2015a, p. 4) de que "sem os movimentos sociais antissistêmicos a defesa de um lugar estratégico para a universidade pública, crítica e autônoma no projeto de nação permanecerá débil e, possivelmente, inviável”. 


\section{REFERÊNCIAS}

ANDES-SN. SINDICATO NACIONAL DOS DOCENTES DAS INSTITUIÇÕES DE ENSINO SUPERIOR, 2016. Dilma sanciona lei que aprofunda privatização de ciência e tecnologia. Disponível em: $<$ http://www.andes.org.br/andes/printultimas-noticias.andes?id=7926>. Acesso em: 20 fev. 2016.

BIANCHI, Álvaro; BRAGA, Ruy. Um conto de duas universidades: quando a lógica mercantil se sobrepõe à construção do pensamento crítico e reflexivo. Revista Cult, 2009. Disponível em: < http://revistacult.uol.com.br/home/2010/03/um-conto-de-duas-universidades/>. Acesso em: 22 set. 2015.

BRASIL. Lei $\mathbf{n}^{\mathbf{0}} \mathbf{1 3 . 2 4 3}$, de 11 de janeiro de 2016. Dispõe sobre estímulos ao desenvolvimento científico, à pesquisa, à capacitação científica e tecnológica e à inovação e altera a Lei no 10.973 , de 2 de dezembro de 2004, a Lei n⿳o 6.815, de 19 de agosto de 1980, a Lei n⿳o 8.666, de 21 de junho de 1993, a Lei no 12.462, de 4 de agosto de 2011, a Lei oํ 8.745, de 9 de dezembro de 1993, a Lei no 8.958, de 20 de dezembro de 1994, a Lei no 8.010, de 29 de março de 1990, a Lei $\mathrm{n}^{\circ}$ 8.032, de 12 de abril de 1990, e a Lei no 12.772, de 28 de dezembro de 2012, nos termos da Emenda Constitucional no 85, de 26 de fevereiro de 2015. Disponível em: < http:/ /www. planalto.gov.br/ccivil_03/_Ato2015-2018/2016/Lei/L13243.htm.> Acesso em: 25 fev. 2016.

BRASIL. Sinopses estatísticas do Censo da Educação Superior: 1995-2015. Brasília: MEC, 2015. Disponível em: <http://www.inep.gov.br/superior/censosuperior/sinopse/ default.asp>. Acesso em: 10 fev. 2016.

BRASIL. Plano Nacional de Pós-graduação 2011-2020. Brasília: CAPES, 2010. Disponível em: <https://www.capes.gov.br/images/stories/download/PNPG_Miolo_ V2.pdf >. Acesso em: 15 fev. 2016.

BRASIL. Decreto $\mathbf{n}^{\mathbf{0}}$ 6.096, de 24 de abril de 2007. Institui o Programa de Apoio a Planos de Reestruturação e Expansão das Universidades Federais - REUNI. Brasília: 2007. Disponível em: <http://www.planalto.gov.br/ccivil_03/_ato2007-2010/2007/decreto/d6096.htm>. Acesso em: 20 fev. 2016.

BRASIL. Decreto n ${ }^{\circ} 5800$, de 8 de junho de 2006. Dispõe sobre o sistema Universidade Aberta do Brasil. Diário Oficial da União, Brasília, DF, 9 jun. 2006. Disponível em: <http://www.planalto.gov.br/civil_03/_ato2004-2006/2006/decreto/d5800.htm>. Acesso em: 26 fev. 2016.

BRASIL. Lei $\mathbf{n}^{\mathbf{0}}$ 11.096, de 13 de janeiro de 2005, 2005a. Institui o Programa Universidade para Todos - PROUNI. Disponível em: <http://www.presidencia.gov.br>. Acesso em: 1 dez. 2015.

BRASIL. Plano Nacional de Pós-Graduação 2005-2010. Brasilia: MEC/Capes, 2005b. Disponível em: <https://www.capes.gov.br/images/stories/download/editais/ PNPG_2005_2010.pdf>. Acesso em: 26 fev. 2016.

BRASIL. Lei $\mathbf{n}^{\mathbf{0}} \mathbf{1 0 . 9 7 3}$, de 2 de dezembro de 2004. Dispõe sobre incentivos à inovação e à pesquisa científica e tecnológica no ambiente produtivo e dá outras providências. Disponível em: <http://www.presidencia.gov.br>. Acesso em: 1 dez. 2015.

BRASIL. Lei $\mathbf{n}^{\mathbf{0}}{ }^{10.172}$, de 9 de janeiro de 2001. Aprova o Plano Nacional de Educação e dá outras providências. Disponível em: < http://www.planalto.gov.br/ccivil_03/leis/ leis_2001/110172.htm>. Acesso em: 20 fev. 2016.

BRASIL. Lei $\mathbf{n}^{\mathbf{0}}$ 9.394, de 20 de dezembro de 1996. Lei de Diretrizes e Bases da Educação Nacional. Disponível em: <http://www.presidencia.gov.br>. Acesso em: 15 dez. 2015.

BRASIL. Plano Diretor da Reforma do Estado. Brasília, DF: MARE, 1995. Disponível 
em: <http://www.bresserpereira.org.br/documents/mare/planodiretor/planodiretor. pdf $>$. Acesso em: 20 fev. 2016.

BRUNO, Lúcia. Educação e desenvolvimento econômico no Brasil. Revista Brasileira de Educação, Rio de Janeiro, v. 16, n. 48, p. 545-561, set./dez. 2011.

BURAWOY, Michael. Ensino superior em crise: o contexto global. Margem Esquerda: ensaios marxistas, São Paulo, n. 25, p. 43-51, out. 2015.

CHESNAIS, François. A finança mundializada: raízes sociais e políticas, configuração e consequências. São Paulo: Boitempo, 2005.

CHESNAIS, François. A mundialização do capital. São Paulo: Xamã, 1996.

DOMINGUES, José Maurício. A conjuntura em duas durações: da crise à disputa do futuro.

Trincheiras, Revista do IBASE, n. 1, abr. 2015. Disponível em: <http://www.academia. edu/12210838/A_conjuntura_em_duas_dura $\%$ C3\%A7\%C3\%B5es_da_crise_\%C3\%A0_ disputa_do_futuro_Trincheiras_no._1_IBASE_abril_2015>. Acesso em: 20 jun. 2016.

LEHER; Roberto. Movimentos sociais, padrão de acumulação e crise da universidade. REUNIÃO NACIONAL DA ANPEd, 37., 2015, Florianópolis. Anais... Florianópolis: Associação Nacional de Pós-graduação e Pesquisa em Educação, 2015a. Disponível em: $<$ http://37reuniao.anped.org.br/wp-content/uploads/2015/02/Trabalho-de-RobertoLeher-para-o-GT11.pdf>. Acesso em: 15 dez. 2015.

LEHER, Roberto. Crise universitária, crise do capital. Margem Esquerda: ensaios marxistas, São Paulo, n. 25, p. 27-35, out. 2015b.

LEHER; Roberto; MOTTA, Vânia Cardoso da. Trabalho docente crítico como dimensão do projeto de universidade. Germinal: Marxismo e Educação em Debate, Salvador, v. 6, n. 1, p. 48-78, jun. 2014.

LIMA, Licínio C. "A melhor ciência": o acadêmico-empreendedor e a produção de conhecimento economicamente relevante. In: CATANI, Afrânio Mendes; OLIVEIRA, João Ferreira de (Org.). Educação superior e produção do conhecimento. Campinas: Mercado de Letras, 2015. p. 11-34.

MANCEBO, Deise; VALE, Andrea Araújo do; MARTINS, Tânia Barbosa. Políticas de expansão da educação superior no Brasil: 1995-2010. Revista Brasileira de Educação (Impresso), v. 20, p. 31-50, jan./mar. 2015.

NETTO, João Paulo; BRAZ, Marcelo. Economia política: uma introdução crítica. São Paulo: Cortez, 2007.

OLIVEIRA, João Ferreira de; FERREIRA, Adriano de Melo; MORAES, Karine Nunes de. A política e a cultura de inovação na educação superior no Brasil. In: CATANI, Afrânio Mendes; OLIVEIRA, João Ferreira de (Org.). Educação superior e produção do conhecimento. Campinas: Mercado de Letras, 2015. p. 127-164.

REIS, Luiz Fernando. Dívida pública, política econômica e o financiamento das universidades federais nos governos Lula e Dilma (2003-2014). Universidade e Sociedade, Brasília, v. 57, p. 16-35, jan. 2016.

RODRIGUES, José. Os empresários e a educação superior. Campinas: Autores Associados, 2007.

SGUISSARDI, Valdemar. Estudo diagnóstico da política de expansão da (e acesso à) educação superior no Brasil: 2002-2012. Piracicaba: 2015. (Mimeo).

SILVA JÚNIOR, João dos Reis. The new Brazilian University: a busca de resultados comercializáveis para quem? São Paulo: Autores Associados, 2016. (No prelo).

SILVA JÚNIOR, João dos Reis; SCHUGURENSKY, Daniel. Refletindo sobre as razões 
da diversificação institucional das universidades estatais brasileiras. Integración y conocimiento, Córdoba/Mercosur Educativo, n. 2, p. 33-48, 2014.

SILVA JÚNIOR, João dos Reis; SPEARS, Eric. Globalização e mudança do papel da universidade federal brasileira: uma perspectiva da economia política. Revista HISTEDBR On-line, Campinas, n. 47, p. 3-23, set. 2012.

SILVA JÚNIOR, João dos Reis; SCHUGURENSKY, Daniel; ARAUJO, Juliana Borges de. Ciencia académica, intelectuales y el trabajo del profesor universitario en Brasil: convergencia y hegemonía. Revista de la Educación Superior, México/DF, v. XLIV (1), n. 173, p. 157 180, ene.-mar. 2015.

SLAUGHTER, Sheila; RHOADES, Gary. Markets in Higher Education. In: ALTBACH, Philip G.; GUMPORT, Patricia J.; BERDAHL, Robert O. (Ed.). American Higher Education in the twenty-first century: social, political and economic challenges. 3. ed. Baltimore: The John Hopkins University Press, 2010. p. 433-464.

\section{NOTAS}

1 "Essa dinâmica, altamente concentradora de riqueza, de acordo com Chesnais (1996), nutre-se de dois mecanismos: a formação de capital fictício, por meio da 'inflação do valor dos ativos' financeiros, e a transferência efetiva de riquezas para a esfera financeira. Tal transferência tem no pagamento da dívida pública e nas políticas monetárias associadas a este um dos seus mecanismos mais importantes. Parcelas cada vez maiores do orçamento dos Estados nacionais têm sido destinadas, por meio da dívida pública, para o circuito da valorização do capital financeiro, em proveito de um restrito grupo de rentistas e algumas grandes empresas transnacionais, beneficiários do processo de financeirização mundializada" (REIS, 2015, p. 19). O mesmo autor calcula que os governos Lula e Dilma destinaram cumulativamente, por meio do Orçamento da União, R \$11,029 trilhões para a dívida pública (juros, amortizações e refinanciamento). Esse montante representou, em média, praticamente metade (49,70\%) dos recursos orçamentários da União, destinados para todas as áreas de atuação governamental (REIS, 2015, p. 23).

${ }^{2} \mathrm{O}$ novo acordo, que seria denominado Acordo sobre Comércio de Serviços (AsCS) ou Trade in Services Agreement (TiSA), atualizaria o Acordo Geral de Comércio e Serviços (AGCS) ora em vigor. Ele deve ter sido discutido na conferência geral da OMC, ocorrida em Nairobi, Kênia, de 15 a 18 de dezembro de 2015. Até o fechamento desse texto não se tinha notícia sobre seu desfecho.

${ }^{3} \mathrm{Na}$ realidade, o Fundo de Financiamento Estudantil (FIES) foi criado pela Lei $\mathrm{n}^{\circ} 10.260$, de 12 de julho de 2001, portanto em data anterior à etapa que se está discutindo no texto. Todavia, em 2010, um conjunto de facilidades foram criadas, de modo que seu uso pôde ser bastante ampliado, por estudantes da rede privada.

${ }^{4}$ Todos os dados estatísticos apresentados neste texto foram retirados de: BRASIL. MEC. INEP. Sinopses estatísticas do Censo da Educação Superior: 1995 a 2015. Brasilia: MEC. Disponível em: < http:// www.inep.gov.br/superior/censosuperior/sinopse/default.asp>. Acesso em: 2 jan. 2016.

${ }^{5}$ Sobre esse aspecto, deve-se registrar que o crescimento do setor privado sobre o público advém desde os tempos da ditadura civil-militar (1964-1984). A situação política daquele período requereu ajustes na educação superior, o que foi feito pela reforma universitária instituída pela Lei n ${ }^{\circ} 5.540$, de 28 de novembro de 1968. Essa legislação reforçou a atuação do então Conselho Federal de Educação (CFE), com forte composição privatista, e as facilidades, 
os incentivos fiscais e tributários para a abertura de IES privadas foram incessantemente criados e recriados. Fato é que, ao fim da ditadura, as matrículas privadas já ultrapassavam em muito as oferecidas nas IES públicas (MANCEBO; VALE; MARTINS, 2015, p. 35).

${ }^{6}$ Valdemar Sguissardi (2015, p. 114) destaca o papel dos fundos de investimento privado (private equity), principalmente transnacionais, com matriz sediada nos EUA, no "preparo" das primeiras empresas brasileiras que visavam abrir o capital e fazer oferta pública inicial de ações (Initial Public Offering - IPO -) na bolsa de valores. Esses fundos investiram quantias altíssimas em empresas educacionais, induziram processos de reestruturação nessas instituições, visando à redução de custos, racionalização administrativa e o uso de gestão claramente empresarial.

${ }^{7}$ Para o aprofundamento dessa temática ver Rodrigues (2007).

${ }^{8}$ Para um maior aprofundamento da situação das universidades norte-americanas, ver o texto de João dos Reis Silva Júnior, Daniel Schugurensky e Juliana Borges de Araujo (2015) ou ainda João dos Reis Silva Júnior (2016). Para esses autores, a origem da tendência de aproximação das universidades norte-americanas com as empresas advém da pressão que as universidades estatais sofreram (e ainda sofrem) para conseguir financiamento que lhes permitisse substituir os cortes estatais. Destacam, ainda, que essas mudanças têm uma dimensão legislativa e discutem os dois principais casos: a promulgação da Bayh-Dohle Act de 1980 e a Competes Act de 2007. O Bayh-Dole Act, ou Lei de Patentes e Licenciamentos, criou uma política de patentes uniforme entre as muitas agências federais que financiam a investigação nos Estados Unidos. Ela permitiu que pequenas empresas e organizações sem fins lucrativos, incluindo as universidades, retivessem a propriedade das invenções obtidas com financiamento do governo federal em programas de investigação (SILVA JÚNIOR; SCHUGURENSKY; ARAUJO, 2015, p. 161-162).

${ }^{9}$ A expressão conhecimento matéria-prima foi adotada por João dos Reis Silva Júnior (2016) numa referência ao trabalho de Sheila Slaughter e Gary Rhoades (2010), que discutem o conhecimento do tipo raw material, para se referir a aquelas produções que podem ser transformadas em produtos, processos ou serviços com o objetivo do aumento da produtividade econômica.

${ }^{10}$ Segundo Silva Júnior (2016), nos EUA, mais recentemente, as corporações passaram também a proteger os artigos, livros e material didático.

Submetido: 04/04/2016

Aprovado: 29/08/2016

Contato:

Deise Mancebo

Rua Barão de Cotegipe 416 casa7, Vila Isabel Rio de Janeiro | RJ | Brasil CEP 20.560-080 
